\title{
Multimodal pricing model in a deficit public transport market: Implication of informal transport
}

\section{Mohamed Dhibi}

Department of Quantitative Economics, Higher Institute of Management of Sousse, Director of Research Laboratory for Management, Innovation and Sustainable Development, University of Sousse, Tunisia

dhibi_mohamed@yahoo.fr

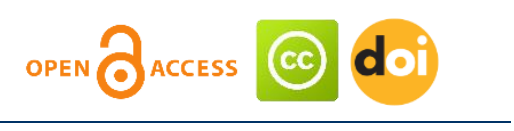

\section{Article history:}

Received: February 11, 2021

1st Revision: March 11, 2021

Accepted: April 23, 2021

\section{DOI:}

10.14254/jsdtl.2021.6-1.5

\begin{abstract}
This article explores one of the most important segments of public transport in developing countries, namely informal transport and its relation to the pricing system of public transport. This paper is an extension of the work of Tirachini, A. and Hensher, D.A., who have developed a model to analyze the impact of non-motorized transport on an optimal public transport pricing policy. We are looking at three congested modes of transportation, and we introduce informal transport as an independent mode of transport instead of nonmotorized transport in this analysis. Informal transport has never been incorporated into an intercity transport pricing analysis and this is the first one that informal transport has been considered an autonomous mode in a pricing model. We tried to show how the pricing policy would change by considering or ignoring the Informal Transport. We propose three congested modes (Public transport, particular vehicular and informal transport) pricing model that incorporates informal transport and reconstruct the impact of a capacity constraint on optimal public transport prices. Pricing model were developed explaining the first best and second best prices and the changes effects of capacities and frequency of public transport bus.
\end{abstract}

Keywords: informal transport, public transport, pricing model, first best and second best models.

\section{Introduction}

In many developing countries, informal transport plays an integral role in people's mobility. Informal transport is private mass transport that operates without regulation and official endorsement (Cervero \& Golub, 2007, Godard \& Ngabmen, 2002, Ferro et al., 2013). In Nairobi (the matatus), informal transport is the primary mode of transport, about $33 \%$ of the total public transport demand was served by Matatus (Takyi, 1990; Cervero, 2000). In Asia, mini- and micro-bus services have historically served from $5 \%$ to $10 \%$ of all trips in India and Thailand and as many as half of all trips in the Philippines (Cervero, 2000). Most informal transport modes are not subject to a fixed route. The amount of flexibility varies; while some vehicles have fixed routes along popular corridors, others generally smaller vehicles,

Corresponding author: Mohamed Dhibi

E-mail: dhibi_mohamed@yahoo.fr

This open access article is distributed under a Creative Commons Attribution (CC-BY) 4.0 license. 
have variable, demand responsive routes. In addition to the routes, the size of the vehicle varies, with vehicles ranging from motorcycles to minibuses. The informal sector almost always delivers paratransit-type services, meaning services are either door-to-door or flexible enough to deviate from standard routes. Pricing is similarly flexible.

Public transport is often considered to be a public good and market products. Public transport pricing systems can reflect a market price, fully operational cost or providing it free of charge. Public funding is an important and sometimes the main contributor to the cost structure of public transportation systems. Transportation pricing policies are often discussed in public debate with close links to attitudes towards freedom, fairness and personal norms. But, in general, public transport pricing is never discussed in the presence of informal transport as an autonomous and competitive mode of transport or a substitutable mode of public transport.

This article explores one of the most important segments of public transport in developing countries, particularly in the African countries, namely informal transport and his relation on the pricing system of public transport. Informal transport plays a vital role in the mobility of people in African countries. It is important to know the mechanisms of this activity, as well as the subtle differences between public transport and the informal transport. Informal transport differs from one country to another and therefore not possible to generalize or extrapolate the knowledge of this sector from one country to another country. Public transport provides people with mobility and access to employment, medical care, services and businesses. To ensure greater accessibility in urban areas, governments must produce an efficient and equitable public transport service. Accessibility in this case relates to the ease of reaching various destinations as measured by the availability of services, speed and affordability. Measures to improve the accessibility of public transport could therefore consist on investments in infrastructure, increasing supply products or introducing public transport pricing system.

The contribution of this paper is twofold. First, we develop a theoretical model, which adds to the literature on the pricing of a congested mode (informal transport) when there is competition between modes that strategically set the price of their transport services (public bus transport). In this model, we take into account three congested modes of transport (public bus, private car and informal transport) that are perceived differently, but the externalities associated to all modes of transport are not taken into account. Based on the literature studied below, and to the best of our knowledge, informal transport has never been incorporated into a intercity transport pricing analysis and this is the first time that informal transport has been considered an autonomous mode in a Pricing model. Secondly, the model fairly accurately reproduces the existing urban situation in most African countries characterized by a supply deficit of public transport, prompting informal transport operators to develop this activity. This model and methodology can be useful in assessing intercity transportation policies in countries with a shortage of public transport systems, and help predict the effects of any regulatory changes or market structure changes (entry of new operators, a new tax).

This paper is organized as follows. The next section briefly reviews previous literature on public transport pricing and informal transport implication. Section 3 presents the assumptions of the built model that takes informal transport into account as a substitute mode of transport for the other two modes of transport. The first best and second best prices are given in Sections 4 and 5. Section 6 presents the analysis and discusses the implications therein, and conclusions are then drawn in the final section of the paper.

\section{Literature review}

The issue of pricing in the presence of informal transport was not subject of any research. In the majority of countries where informal transport is already present, bus activities are owned by government, through public transport companies. Bus supply levels are instruments for regulating and maximizing social welfare (De Borger and Wouters, 1998). The urban transport pricing studies differ in terms of the amount of spatial, temporal and modal detail in the representation of urban transport, as well as in the transport cost components that are taken into account. In this paper, the urban transport system is represented by many transport markets (rail modes, road modes). Demand is an aggregate representation of the choices of transport users. The demand for passenger transport is generated by assuming that a representative group of people optimally divide their generalized revenues between transport and other goods. Many passenger transport services are available: bus, passenger cars and 
informal transport. We do not distinguish here between peak and off-peak travel and we consider three available modes: bus, particular vehicle and informal transport.

Given the structure of the transport market, what is the optimal structure of services to be offered to bus passengers? More precisely, what is the optimal frequency of services and at what price should be applied when we take into account the informal transport? We try to answer to the effect of including informal transport alternatives in the optimal pricing of motorized modes (public transport and car)?

The literature on optimal public transport pricing, frequencies and vehicle sizes is abundant (Glaister \& Lewis, 1978; Small, 1983; Viton, 1983; Kraus, 1989; De Borger et al., 1997). De Borger et al. (1998) and Proost and Van Dender (2001)) but we found the lack of treatment of informal transport effect on optimal public transport pricing. Quinet (2005) in the analysis of the transport pricing system distinguishes between the first best (in which all prices correspond to marginal costs) and the second best policies. A historical review on the research developed on public transport pricing policy shows that there has been an evolution to increasingly integrate transport externalities into the analysis. Mohring (1972) works on optimal frequencies. Jansson $(1993,1997)$ extends the model to look into the optimal fleet size and vehicle size in multiple periods. Viton (1983), De Borger, Wouters (1998) and Bly, P., Oldfield, R.(1986) incorporate externalities other than congestion in their evaluation of optimal pricing and characteristics of transit supply. Another strand of literature (Kraus (1991), Tirachini et al. (2012)) focuses on the effects crowding externalities, confirming the importance of crowding in the evaluation of transport policies. Arnott and Yan (2000) examine a two-mode problem, where both modes are subject to congestion and there is no congestion interaction between them, and study the joint optimization of prices, road capacity and rail capacity. Others papers of Verhoef et al. (1997) and Ivaldi and Vibes (2008)) devoted their analysis to an interurban setting. Verhoef et al. (1997) discusses the social feasibility of road pricing for users. Ivaldi and Vibes (2008) analyze inter- and intra-modal competition in intercity passenger transport markets.

The analysis of transport pricing schemes usually distinguishes between first best and second best policies. A situation in which all prices match marginal costs is known as first best. As reviewed by Quinet (2005) and Tirachni et al (2012), for the first best world there are no external effects, no public goods, firms are price-takers, there is no tax or taxes are optimal, there is no uncertainty or asymmetry in information, no redistribution problems.... However, transport systems in the reality do not match all these conditions and several departures can be found, such as the influence of external factors, noncompetitive markets... associated with a condition known as second best. Technological or acceptability constraints are common factors that impose second best situations within the transport sector, given the impossibility of taxing at marginal cost all modes or all locations in a network.

The first best fare is the one that maximizes social welfare, defined as the sum of users' and operators' benefit (Mohring (1972), Turvey and Mohring (1975) and Jansson (1997), Quinet (2005), Börjesson. M., Man Fung. C., Proost. S. (2017)). The social optimum, where both travelers' benefits and firm's profits are taken into account, is considered first. Socially optimal prices equate marginal costs that can be considered null in the case of road transportation. Socially optimal frequencies are such that the travelers' waiting time costs equate the average (production) costs.

Informal transport or paratransit or Intermediate Public Transport (IPT), is an important component of its overall transport services, is not considered a self-sustaining transport mode in pricing research. In the literature, several researches on informal transport (Cervero, 2000; Cervero et al., 2007; Parry et al., 2010; Godard et al., 2002; Chavis \& Daganzo, 2013) analyze the characteristics of informal transport, its social and economic role, barriers to entry, production capacity, etc., but the role of informal transport in determining the optimal price of public transport, the relationship between public transport and informal transport are not treated in these researches. However, there is no clear vision of what would be an efficient structure of public transport services in the presence of informal transport. Specifically, what should be the frequency of public transport services and how should these fares be? This paper aims at answering, at least partially, these questions.

Informal transport as a result of the malfunctioning of public transport, it is a recognized mode of transport in developing countries and is an alternative that is available to users. The question of the influence of informal transport on urban transport pricing policy is not addressed and no attempt is made to determine how the pricing policy would change by considering or ignoring the transport Informal. We propose a model that incorporates informal transport and reconstructs the impact of a capacity constraint on optimal public transport prices. 


\section{Model assumptions}

In several developing countries (Asia, Africa, Latin America), informal transport is a highly responded modal alternative. We consider in this analysis a single origin-destination pair and three modes: Private car (VP), Public Transport (TP) which could be a bus, and informal transport (TI) (minibus, Foulafoula, Cladestin...). In our model, we assume that the informal transport mode is an alternative to the choice of a motorized mode. The competitiveness of informal transport depends on these performances and the quality of the service offered...In all situations, informal transport as a substitute for conventional motorized modes generally increases as the capacity of public transport decreases and its quality in terms of speed decreases as well.

In the model, we follow much of the notation of Small and Verhoef (2007), Mirabel. F (1999), Pederson (2003) and Tirachini, A. and Hensher, D.A. (2012). We consider that the operating period is normal, i.e. we do not take into account peak periods, which allow us to find closed formulas for the optimum prices of the private car, public transport and informal transport, to inform the impact of the constraints of specificity of each mode of transport on the pricing policy. Road capacity is fixed and tax distortions are ignored. The decision variables are the optimal prices for the passenger car and public transport, as well as the frequency and capacity of buses or trains.

In this model we ignore the income effect and the level of the economy. The road capacity and taxes are fixed. The joint demand function of the three modes can be obtained from the benefit function $B\left(\mathrm{~s}_{v p}, \mathrm{~s}_{t p}, \mathrm{~s}_{t i}\right)$, which expresses the consumers' willingness to pay for a particular combination $\left\{\mathrm{s}_{v p}, \mathrm{~s}_{t p}\right.$, $\left.\mathrm{s}_{t i}\right\}$ of travel by automobile, public transport and transport informal. The inverse demand function $d_{i}$ for mode $i$ is given by:

$$
d_{i}\left(s_{v p}, s_{t p}, s_{t i}\right)=\frac{\partial B\left(s_{v p}, s_{t p}, s_{t i}\right)}{\partial s_{i}} \quad ; \quad i=\{v p, t p, t i\}
$$

For the cost function, we only take into account the cost of time and operating costs. Let $C_{i}$ the total cost function and $c_{\mathrm{i}}$ the average cost function of mode $i$, is given by:

Let us consider that

$$
C_{i}=s_{i} c_{i} \text { when } i=(v p, t c, t i)
$$

$$
c_{v p}\left(\mathrm{~s}_{v p}, \mathrm{~s}_{t p}, \mathrm{~s}_{\mathrm{ti}}, f_{t p}, K_{\mathrm{tp}}\right), c_{t p}\left(s_{v p}, \mathrm{~s}_{t p}, \mathrm{~s}_{\mathrm{ti}}, f_{t p}, K_{\mathrm{tp}}\right) \text { and } c_{t i}\left(s_{v p}, \mathrm{~s}_{t p}, \mathrm{~s}_{\mathrm{ti}}, f_{t p}, K_{\mathrm{tp}}\right)
$$

are the average cost of particular vehicle, bus travel and transport informal respectively.

We assume that the mode of public transport is a bus that shares the right of way with cars and informal transport, resulting in a dependency of congestion between the three modes. Buses running on segregated bus ways are a special case that will not be dealt with in this paper. We also consider that the three modes of transport use the same road infrastructure and the informal transport mode competes directly with the particular car and buses, and its capacity is not limited since it is a factor of adjustment of the transportation system in general. We assume that these cost functions depend on the demand $\mathrm{s}_{v p}$, bus frequency $f_{b}$ and capacity $K_{b}$ related to bus size, demand $\mathrm{s}_{t p}$ increases with crowding, demand $\mathrm{s}_{\mathrm{ti}}$ that increases with the sub-offer of public transport. The relationship between car demand $\mathrm{s}_{v p}$ and car flow $f_{v p}$ is $f_{v p}=u_{v p} \mathrm{~S}_{v p}$, where $u_{v p}$ is the inverse of the average occupancy rate per car. Bus cost $c_{t p}$ includes users cost $c_{u}$ : access, waiting and in-vehicle time costs; and operator cost $c_{o}$ which depends on bus frequency and size, hence

$$
c_{t p}=c_{u}+c_{0}
$$

Transport informal cost $c_{t i}$ includes users fixed cost $c_{i}$ (access, waiting and in-vehicle time costs, These costs of informal transport are perceived to be lower than those of public transport) and operator cost $c_{v}$ which depends on frequency, maintenance and reparation of the vehicle, hence

$$
c_{t i}=c_{i}+c_{v}
$$

The Social welfare function SW (6), maximized subject to an effective capacity constraint for public transport vehicles, given by the expression (7), which stipulates that the capacity of public transport is always maintained below the total demand $s_{t p}$ (under transport offer i.e. actual offer is under actual demand).

$$
\mathrm{SW}=\mathrm{B}\left(\mathrm{s}_{\mathrm{vp}}, \mathrm{s}_{\mathrm{tp}}, \mathrm{s}_{\mathrm{ti}}\right)-\mathrm{s}_{\mathrm{vp}} \mathrm{c}_{\mathrm{vp}}\left(\mathrm{s}_{\mathrm{vp}}, \mathrm{s}_{\mathrm{tp}}, \mathrm{s}_{\mathrm{ti}},\right)-\mathrm{s}_{\mathrm{tp}} \mathrm{c}_{\mathrm{tp}}\left(\mathrm{s}_{\mathrm{vp}}, \mathrm{s}_{\mathrm{tp}}, \mathrm{s}_{\mathrm{ti}}\right)-\mathrm{s}_{\mathrm{ti}} \mathrm{c}_{\mathrm{ti}}\left(\mathrm{s}_{\mathrm{vp}}, \mathrm{s}_{\mathrm{tp}}, \mathrm{s}_{\mathrm{ti}}\right)
$$

Under constraint:

$$
s_{t p} \geq f_{t p} k_{t p}
$$


In equilibrium, the marginal benefit is equal to the generalized price, $c_{v p}+\tau_{v p} ; c_{t p}+\tau_{t p}$ and $c_{t i}+$ $\tau_{t i}$ for particular vehicle, public transport and informal transport respectively, where $\tau_{v p}$ is the road use charge for the automobile, $\tau_{t p}$ is the fare for public transport and $\tau_{t i}$ is the road use charge for informal transport. We assume that the mode of public transport (bus) shares the right of way with passenger cars and with informal transport, which leads to a dependency of congestion between the three modes.

$$
\frac{\partial B}{\partial s_{v p}}=c_{v p}+\tau_{v p} ; \frac{\partial B}{\partial s_{t p}}=c_{t p}+\tau_{t p} \text { and } \frac{\partial B}{\partial s_{t i}}=c_{t i}+\tau_{t i}
$$

\section{First best pricing}

To solve constraint-maximization problems, we consider the following Lagrange function:

$$
\begin{aligned}
& L=B\left(s_{v p}, s_{t p}, s_{t i}\right)-s_{v p} c_{v p}\left(s_{v p}, s_{t p}, s_{t i}, f_{t p}, k_{t p}\right)-s_{t p} c_{t p}\left(s_{v p}, s_{t p}, s_{t i}, f_{t p}, k_{t p}\right)- \\
& s_{t i} c_{t i}\left(s_{v p}, s_{t p}, s_{t i}, f_{t p}, k_{t p}\right)+\lambda\left(s_{t p}-f_{t p} k_{t p}\right)
\end{aligned}
$$

Where $\lambda$ is the Lagrange multiplier associated with constraint (5), which represents the marginal social benefit when increasing the production capacity of bus by one unit. The application of the first order conditions allows us to conclude the following (see appendix 1):

and

$$
\tau_{v p=s_{v p}} \frac{\partial c_{v p}}{\partial s_{v p}}+s_{t p} \frac{\partial c_{t p}}{\partial s_{v p}}+s_{t i} \frac{\partial c_{t i}}{\partial s_{v p}}
$$

$$
\tau_{t i}=s q_{t i} \frac{\partial c_{t i}}{\partial s_{t i}}+s_{t p} \frac{\partial c_{t p}}{\partial s_{t i}}+s_{v p} \frac{\partial c_{v p}}{\partial s_{t i}}
$$

The equation (10) represents the Pigouvian tax of cars. The second term is the marginal cost on bus cost due to car demand and the third term is the marginal cost on informal transport do to use of the particular vehicle on the road. In The equation (11), the second term is the marginal cost on bus due to informal transport demand and the third term is the marginal cost on particular vehicle due to informal transport demand. In this spirit of reasoning, the optimal solution for bus fare, frequency and capacity depends on the capacity constraint that is binding. In this case Lagrange multiplier $\lambda \neq 0$.i.e that's means the optimal fare is obtained as:

$$
\tau_{t p}=c_{o}+s_{v p} \frac{\partial c_{v p}}{\partial s_{t p}}+s_{t p} \frac{\partial c_{t p}}{\partial s_{t p}}+s_{t i} \frac{\partial c_{t i}}{\partial s_{t p}}-\lambda
$$

From Equation (A5), the marginal welfare benefit of capacity can be expressed as:

$$
\begin{gathered}
\lambda=\frac{1}{K_{t p}}\left(s_{v p} \frac{\partial c_{v p}}{\partial f_{t p}}+s_{t p} \frac{\partial c_{t p}}{\partial f_{t p}}+s_{t i} \frac{\partial c_{t i}}{\partial f_{t p}}\right) \\
\text { Using } s_{t p}=f_{t p} k_{t p} \Rightarrow \frac{f_{t p}}{s_{t p}}=\frac{1}{k_{t p}} \\
\tau_{t p}=c_{o}+s_{v p} \frac{\partial c_{v p}}{\partial s_{t p}}+s_{t p} \frac{\partial c_{t p}}{\partial s_{t p}}+s_{t i} \frac{\partial c_{t i}}{\partial s_{t p}}+f_{t p}\left(\frac{s_{v p} \partial c_{v p}}{s_{t p} \partial f_{t p}}+\frac{\partial c_{t p}}{\partial f_{t p}}+\frac{s_{t i} \partial c_{t i}}{s_{t p} \partial f_{t p}}\right)
\end{gathered}
$$

In the situation of a country where informal transport is plentiful and the public operator is unable to increase the production capacity of buses, the only possibility is to increase the frequency of buses to satisfy the excesses and effective demand (6). The equation (14) expresses the relationship between bus frequency and optimal bus fare. This frequency of buses expressed in terms of the number of seats offered, which is generally unfulfilled, will be rewarded by the offer of informal transport. In this equation, the term within the brackets is positive and represents the impact of the increased frequency needed to deal with excess demand on the marginal costs of the car and bus. But the key question is what advantage can be drawn if we increase the frequency of buses? However, note that the frequency and capacity can be optimal and the capacity constraint can actually be binding. But when there is no additional benefit of providing excess capacity i.e. no comfort improvement and no overcrowding of buses, in this case, when the frequency has been optimized, the actual size of the vehicle is considered as the minimum that satisfies the equation (6). In the latter case, the expression (14) is still valid, but the term relative to the capacity in the brackets is zero because the frequency is optimal, then equation (14) is reduced to the optimum fare without capacity constraints. When the public operator sees that it is necessary to increase the frequency of buses, the optimal frequency and capacity are obtained by solving the following system of equations:

$$
s_{t p} \frac{\partial c_{t p}}{\partial f_{t p}}+s_{v p} \frac{\partial c_{v p}}{\partial f_{t p}}+s_{t i} \frac{\partial c_{t i}}{\partial f_{t p}}=0
$$




$$
s_{t p} \frac{\partial c_{t p}}{\partial k_{t p}}+s_{v p} \frac{\partial c_{v p}}{\partial k_{t p}}+s_{t i} \frac{\partial c_{t i}}{\partial k_{t p}}=0
$$

The most important result that can be drawn is that the public operator does not have the financial or technical possibilities to increase these transport capacities immediately but on the other hand he must reach the optimum buses frequency to meet the demand Excess. The public operator is then in an optimal frequency situation and in direct competition with the informal transport, which itself operates in a situation of optimality. Informal transport, which operates in a competitive situation, defines its optimal frequency and optimal production capacity according to the capacity and optimal frequency of the public operator's buses. In this case, the public operator defines optimal rates always taking into account the capacity constraint that is usually binding. The optimal frequency depends on the congestion situation and several external factors that we will not take them into account in this analysis.

\section{Second best pricing}

When we consider that no road price for particular vehicle was applied, the same problem can be solved and the Lagrange function becomes:

$$
\begin{array}{r}
L=B\left(s_{v p}, s_{t p}, s_{t i}\right)-s_{v p} c_{v p}\left(s_{v p}, s_{t p}, s_{t i}, f_{t p}, k_{t p}\right)-s_{t p} c_{t p}\left(s_{v p}, s_{t p}, s_{t i}, f_{t p}, k_{t p}\right)- \\
s_{t i} c_{t i}\left(s_{v p}, s_{t p}, s_{t i}, f_{t p}, k_{t p}\right)+\lambda\left(s_{t p}-f_{t p} k_{t p}\right)+\gamma_{v p}\left(c_{v p}-\frac{\partial B}{\partial s_{v p}}\right)+\gamma_{t p}\left(c_{t p}+\tau_{t p}-\frac{\partial B}{\partial s_{t p}}\right)+ \\
\gamma_{t i}\left(c_{t i}-\frac{\partial B}{\partial s_{t i}}\right)
\end{array}
$$

In the case of public transport pricing, the situation we are dealing with concerns buses that compete with low-priced informal transport, which imposes a second best constraint when determining Public transport tariffs. The classic argument is that if informal transportation is offered at competitive prices, there will be a surplus of travel demand for informal transportation; Therefore, it is necessary to improve the welfare of individuals by, on the one hand, the reduction of the public transport tariff in order to attract certain users of passenger cars and informal transport to buses, on the other hand, by the reduction Level of congestion and other traffic externalities on the road network. This situation Justify the second best pricing by public transport subsidy, after the first best pricing (Preston, (2008); Parry and Small, (2009)). As argued by Parry, I. and A. Bento (2001) and Small (2004), the first and second best tariff analysis, congestion charging could be seen as a means of reducing the financial needs of public transport, as an optimum road charge should decrease the subsidy required for public transport, even if the revenue from road pricing is not earmarked for public transport.

The second derivative of the inverse of demand $d_{i}$ obtained from the equation (1) represents the marginal change in willingness to pay for mode $i$ due to a marginal change in the amount of travel on mode $j$. In our case, the three modes of transport are substitutable (if public transport tariffs thus increases demand for VP and informal transport also increase), this is why the second derivative must be different from zero. After many manipulation and simplification (see appendix 2) the second best bus fare is:

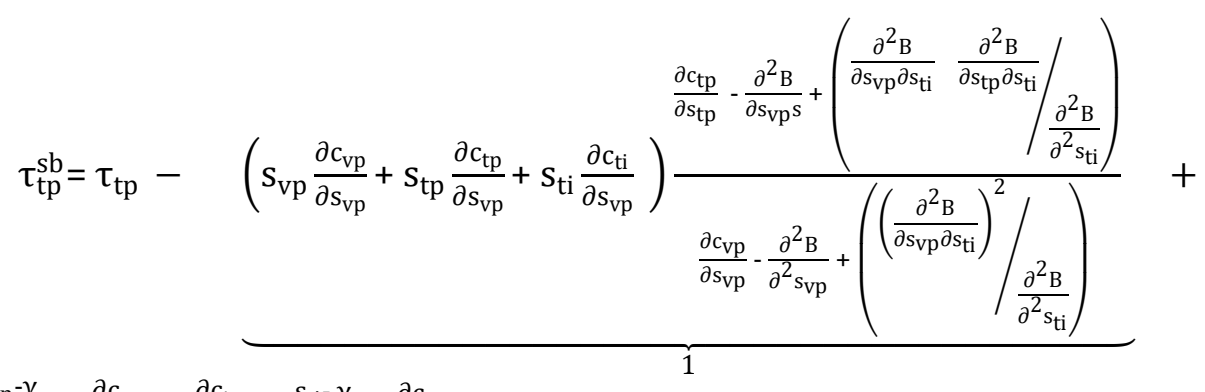

$$
\begin{aligned}
& \underbrace{f_{\mathrm{tp}}\left(\frac{\mathrm{s}_{\mathrm{vp}}-\gamma_{\mathrm{vp}}}{\mathrm{s}_{\mathrm{tp}}} \frac{\partial \mathrm{c}_{\mathrm{vp}}}{\partial f_{\mathrm{tp}}}+\frac{\partial c_{\mathrm{tp}}}{\partial f_{\mathrm{tp}}}+\frac{\mathrm{s}_{\mathrm{ti}}-\gamma_{\mathrm{ti}}}{\mathrm{s}_{\mathrm{tp}}} \frac{\partial \mathrm{c}_{\mathrm{ti}}}{\partial f_{\mathrm{tp}}}\right)}_{2}
\end{aligned}
$$

The second best pricing ${ }^{1}$ is expressed above in equation 18 . The informal transport is a substitute for public transport modes or particular car. Mathematically the substitution parameters between these different modes are expressed at the level of equation (18) by the second derivatives $\partial^{2} B_{t p \rightarrow t i}, \partial^{2} B_{v p \rightarrow t i,} \partial^{2} B_{t p \rightarrow v p}$. Theses expressions explain the interactions between the

1 The first order conditions for solving the equation are given in Appendix (2). 
three competitive and substitutable modes. In a context of public transport sub-offer, it is logical that the three modes are substitutable and each of these modes is chosen according to its intrinsic characteristics. If particular vehicle (VP) does not interact with the buses (tp), and at the same time the informal transport (ti) does not interact with the buses (tp), the second derivative $\partial^{2} B_{t p \rightarrow t i}=$ $0 ; \partial^{2} B_{v p \rightarrow t i}=0 ; \partial^{2} B_{t p \rightarrow v p}=0$ and the second term of the equation (18) is null (the second-best correction is zero: second term on the right-hand side of Equation (18)), in this case the second best fare is equal to the first best fare (14). In other words, if there is no substitution between modes, the second best fare equation equalizes the first best fare equation (18) $=(14)$. The second best fare is equal to first best fare $\tau_{\mathrm{tp}}^{\mathrm{sb}}=\tau_{\mathrm{tp}}$ when the second best correction is zero, i.e. the terms (1) and (2) in the equation (18) are equals $(1=2)$.

$$
\left(s_{\mathrm{vp}} \frac{\partial c_{\mathrm{vp}}}{\partial s_{\mathrm{vp}}}+s_{\mathrm{tp}} \frac{\partial c_{\mathrm{tp}}}{\partial s_{\mathrm{vp}}}+s_{\mathrm{ti}} \frac{\partial c_{\mathrm{ti}}}{\partial s_{\mathrm{vp}}}\right) \frac{\frac{\partial c_{\mathrm{tp}}}{\partial s_{\mathrm{tp}}}-\frac{\partial^{2} \mathrm{~B}}{\partial s_{\mathrm{vp}} \partial s_{\mathrm{tp}}}+\left(\frac{\partial^{2} \mathrm{~B}}{\partial s_{\mathrm{vp}} \partial s_{\mathrm{ti}}} \frac{\partial^{2} \mathrm{~B}}{\partial s_{\mathrm{tp}} \partial s_{\mathrm{ti}}} / \frac{\partial^{2} \mathrm{~B}}{\partial^{2} s_{\mathrm{ti}}}\right)}{\frac{\partial c_{\mathrm{vp}}}{\partial s_{\mathrm{vp}}}-\frac{\partial^{2} \mathrm{~B}}{\partial^{2} s_{\mathrm{vp}}}+\left(\left(\frac{\partial^{2} \mathrm{~B}}{\partial s_{\mathrm{vp}} \partial s_{\mathrm{ti}}}\right)^{2} / \frac{\partial^{2} \mathrm{~B}}{\partial^{2} s_{\mathrm{ti}}}\right)}=f_{\mathrm{tp}}\left(\frac{s_{\mathrm{vp}}-\gamma_{\mathrm{vp}}}{s_{\mathrm{tp}}} \frac{\partial c_{\mathrm{vp}}}{\partial f_{\mathrm{tp}}}+\frac{\partial c_{\mathrm{tp}}}{\partial f_{\mathrm{tp}}}+\frac{s_{\mathrm{ti}}-\gamma_{\mathrm{ti}}}{s_{\mathrm{tp}}} \frac{\partial c_{\mathrm{ti}}}{\partial f_{\mathrm{tp}}}\right)
$$

In this case, we assume that there is no substitution between modes $t p$ and $t i$, and $v p$ and $t i$ then $\frac{\partial^{2} B}{\partial s_{v p} \partial s_{t i}}=\frac{\partial^{2} B}{\partial t p} \partial_{t i}=\frac{\partial^{2} B}{\partial s_{v p} \partial s_{t p}}=0$, which we consider the second best bus fare considering only two modes (vp and tp), i.e., in this case there is no distinction between private car and informal transport. This result was obtained by Small and Verhoef (2007) and Ahn (2009) for the case in which there is no congestion interaction between modes. This situation is reflected in equation (18) by the equal marginal costs of the two modes, i.e.

$$
\frac{\partial c_{t p}}{\partial s_{t p}}=\frac{\partial c_{t v}}{\partial s_{t v}}=0
$$

Thus, we can consider that the bus demand does not affect the travel time of the car, so there will be no substitution between modes and the structure of the market is generally stationary. This remains valid as long as the production capacity has not evolved. As long as the production capacity of the buses is constant, the travel times of the other modes do not change, so there will be no changes in the generalized costs of these modes, i.e.

$$
\frac{\partial c_{v p}}{\partial f_{t p}}=\frac{\partial c_{t p}}{\partial f_{t p}}=\frac{\partial c_{t i}}{\partial f_{t p}}=0
$$

If the cross demand elasticity between particular vehicle and the bus, and the cross demand elasticity between the bus and the informal transport are zero, i.e. $\partial^{2} B_{t p \rightarrow t i}=0 ; \partial^{2} B_{t p \rightarrow v p}=0$, the second best bus fare is equal to the first best price $\left(\tau_{t p}^{S B}=\tau_{t p}\right)$ even though a fares applied to the bus is low, does not change the market structure and the shares of each mode. On the other hand, if $\frac{\partial c_{t p}}{\partial s_{t p}} \neq$ 0 or $\frac{\partial c_{t v}}{\partial s_{t v}} \neq 0$ in this case, the second best fare (18) is not equal to the first best fare even if the cross demand elasticities between the three modes are zero. For a fixed level of congestion, Tirachini, A. and Hensher, D.A.(2012), Proost, S. and K. Van Dender (2008) have shown that the second best bus fare is higher than the first best fare when we intervene in our analysis three modes of transport (bus, private vehicle, informal transport ) instead of two modes (bus, private vehicle). This conclusion remains valid as long as we do not take into account the congestion situation and the negative externality factors. This rule that we have just shown in this paper remains valid as long as we do not take into account the external factors (congestion, taxation, pollution).

If equation (19) is not checked, i.e. the second best correction is not equal zero, and the second best fares is not equal to the first best fares $\tau_{\mathrm{tp}}^{\mathrm{sb}} \neq \tau_{\mathrm{tp}}$. When the correction factor (2) of equation (18) exceeds the correction factor (1), the second best fares exceeds the first best fares $\tau_{\mathrm{tp}}^{\mathrm{sb}} \geq \tau_{\mathrm{tp}}$. This situation is expressed in the equation below: 


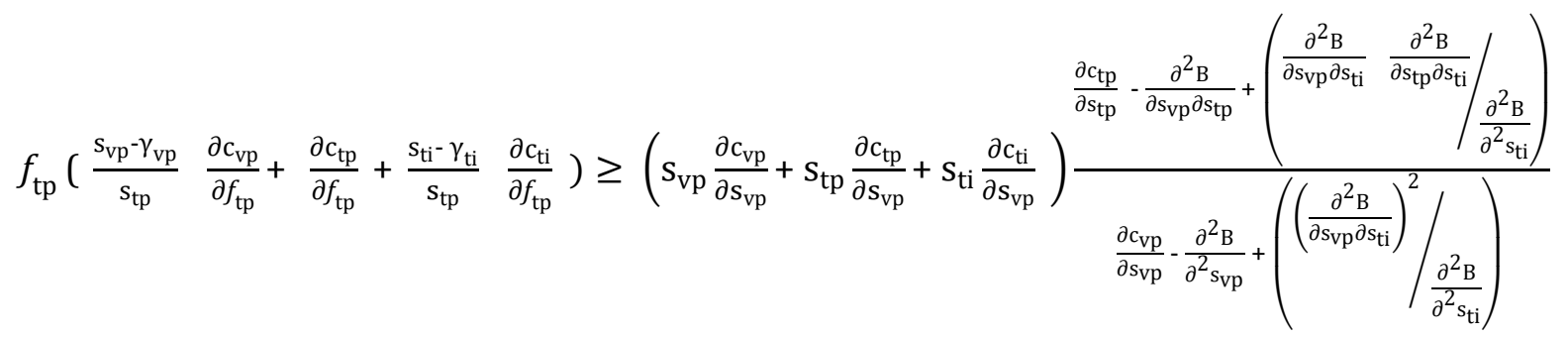

When the cross-elasticity between the public transport and the informal transport is high $\left(\frac{\partial^{2} \mathrm{~B}}{\partial \mathrm{s}_{\mathrm{tp}} \partial \mathrm{s}_{\mathrm{ti}}}\right)$, and the cross -elasticities between private cars and informal transport and between public transport and private cars $\left(\frac{\partial^{2} \mathrm{~B}}{\partial \mathrm{s}_{\mathrm{vp}} \partial \mathrm{s}_{\mathrm{ti}}} ; \frac{\partial^{2} \mathrm{~B}}{\partial \mathrm{s}_{\mathrm{vp}} \partial \mathrm{s}_{\mathrm{tp}}}\right)$ are low (in values absolute), we can see that the second best fares is higher than the first best fares $\left(\tau_{\mathrm{tp}}^{\mathrm{sb}} \geq \tau_{\mathrm{tp}}\right)$. In other words, when the modal substitution between public transport and informal transport is higher than the substitution between public transport and private cars, it is noted that a high fares of public transport attracts more passengers to the informal transport. On the other hand a low public transport fares attracts more passengers to public transport. But, we note that the change could go to the other way as well $\left(\tau_{\mathrm{tp}}^{\mathrm{sb}} \leq \tau_{\mathrm{tp}}\right)$ if the modal substitution between the automobile and the informal transport is stronger than between public transport and informal transport (low values of $\frac{\partial^{2} \mathrm{~B}}{\partial \mathrm{s}_{\mathrm{vp}} \partial \mathrm{s}_{\mathrm{ti}}} ; \frac{\partial^{2} \mathrm{~B}}{\partial \mathrm{s}_{\mathrm{tp}} \partial \mathrm{s}_{\mathrm{ti}}}$ ). To point out, that these conclusions depend on the optimal frequency and the capacity of the public buses. But the main question is whether or not the operator provides the optimal transport capacity? And the optimal frequency?

Optimal frequency and bus capacity ${ }^{2}$ are the solution of equation below:

$$
\begin{aligned}
& \left(s_{v p}-\gamma_{v p}\right) \frac{\partial c_{v p}}{\partial f_{t p}}+\left(s_{t p}-\gamma_{t p}\right) \frac{\partial c_{t p}}{\partial f_{t p}}+\left(s_{t i}-\gamma_{t i}\right) \frac{\partial c_{t i}}{\partial f_{t p}}=0 \\
& \left(s_{v p}-\gamma_{v p}\right) \frac{\partial c_{v p}}{\partial k_{t p}}+\left(s_{t p}-\gamma_{t p}\right) \frac{\partial c_{t p}}{\partial k_{t p}}+\left(s_{t i}-\gamma_{t i}\right) \frac{\partial c_{t i}}{\partial k_{t p}}=0
\end{aligned}
$$

It is very important to indicate that $\left.\left.\gamma_{v p}=\frac{\left(\mathrm{s}_{\mathrm{vp}} \frac{\partial c_{\mathrm{vp}}}{\partial s_{\mathrm{vp}}}+s_{\mathrm{tp}} \frac{\partial c_{\mathrm{tp}}}{\partial s_{\mathrm{vp}}}+s_{\mathrm{t}} \frac{\partial c_{\mathrm{ti}}}{\partial s_{\mathrm{vp}}}\right)}{\left(\left(\partial^{2}{ }^{2}\right.\right.}\right)^{2}\right)$ represents the second best

$$
\frac{\partial c_{\mathrm{vp}}}{\partial s_{\mathrm{vp}}}-\frac{\partial^{2} \mathrm{~B}}{\partial^{2} s_{\mathrm{vp}}}+\left(\left(\frac{\partial^{2} \mathrm{~B}}{\partial s_{\mathrm{vp}} \partial s_{\mathrm{ti}}}\right)^{2} / \frac{\partial^{2} \mathrm{~B}}{\partial^{2} s_{\mathrm{ti}}}\right)
$$

case the congestion externality of buses to cars, and is less internalized because $\gamma_{v p}>0$. If there is no congestion interaction, and no cross congestion, i.e. $\frac{\partial c_{v p}}{\partial f_{t p}}=0 ; \frac{\partial c_{t p}}{\partial f_{t p}}=0 ; \frac{\partial c_{t i}}{\partial f_{t p}}=0$, the rules for first-best and second-best frequ and bus capacity are the same. But in general, there is a negative effect of buses on travel time by cars and informal transport must be noted and which are expressed by: $\frac{\partial c_{v p}}{\partial f_{t p}} \neq$ 0 and $\frac{\partial c_{t i}}{\partial f_{t p}} \neq 0$ which shows that the first-best and second-best fares are different.

\section{Conclusion}

In this paper we focus on the economic fundamentals of pricing policies and their implication on the pricing policy. We have developed a model to analyze the informal transport and their implication on the transport market structure. It is shown that the effect of considering the informal transport mode on optimal public transport fares depends on the demand substitution between modes. The potential substitution between public bus and informal transport should be considered when estimating the second-best public transport fare. If the modal substitution between public transport and informal transport is strong relative to the substitution between public bus transport and car, and between car and informal transport, it is more likely that the optimal public transport fare was underestimated if informal transport is ignored. When we derive the second-best bus fare with explicit account of cars and

\footnotetext{
2 Relation between optimal frequency and capacity of bus and optimal frequency and capacity of informal transport will be studied in a future paper.
} 
informal transport, we obtain analytically the conditions that lead to the underestimation or overestimation of the optimal bus fare.

When bus fares are set at the optimum without any improvement in quality, the substitution between public buses and informal transport becomes greater than the substitution between the automobile and public transport, i.e., we will have a change in market structure and additional demand for informal transport. Passengers consider the quality of informal transport service is better than the quality of public bus transport service. The optimal pricing of bus transport limits the substitution between the three modes of transport taken in this analysis and determines the structure of the transport market in general.

We have revisited that the capacity constraint in public transport service is very important, and plays a role in optimal pricing when bus capacity can be set at its optimum level. In developing countries, the public transport operator does not have the financial and technical means to instantly increase these production capacities to meet excess demand, but it must maintain an optimal frequency of buses to satisfy it. In fact, if public transport companies are working at their optimum capacity and with optimal frequency, but as long as the quality of service is poor, there will be a reorganization of the market by the substitution effect between public bus and informal transport on the one side, and private cars on the other. This situation forces public transport companies not to apply optimal fares in order to maintain its attractiveness and retain its customers.

Future research needs to explore the significant role of the informal transport quality and its implications on optimal pricing of public transport. The relationship between quality of informal transport, buses congestion and pricing on public transport needs to be better understood. Relations between optimal frequency and capacity of public buses and optimal frequency and capacity of informal transport must be studied. Many search trails with a special qualification related to informal transport need to be explored (congestion, accident externalities, optimal investment in public transport infrastructure...). The characteristics of supply and pricing strategies of informal transport operators will need to be studied. This research will provide statistical confirmation and qualitative of previous findings around the factors influencing informal transport supply, and must add significant new insights that can help shape more effective responses to the mobility challenge.

\section{Citation information}

Dhibi, M. (2021). Multimodal pricing model in a deficit public transport market: Implication of informal transport. Journal of Sustainable Development of Transport and Logistics, 6(1), 59-71. doi:10.14254/jsdtl.2021.6-1.5.

\section{References}

Ahn, K. (2009). Road pricing and bus service policies. Journal of Transport Economics and Policy (JTEP), 43(1), 25-53.

Arnott, R., \& Yan, A. (2000). The two-mode problem: Second-best pricing and capacity. Review of Urban \& Regional Development Studies, 12(3), 170-199.

Bly, P. H., \& Oldfield, R. H. (1986). Competition between minibuses and regular bus services. Journal of Transport Economics and Policy, 47-68.

Bly, P. H., Webster, F. V., \& Pounds, S. (1980). Effects of subsidies on urban public transport. Transportation, 9(4), 311-331.

Börjesson, M., Fung, C. M., \& Proost, S. (2017). Optimal prices and frequencies for buses in Stockholm. Economics of Transportation, 9, 20-36.

Cervero, R. (2000). Informal transport in the developing world. UN-HABITAT.

Cervero, R., \& Golub, A. (2007). Informal transport: A global perspective. Transport policy, 14(6), 445457.

Chavis, C., \& Daganzo, C. F. (2013). Analyzing the structure of informal transit: The evening commute problem. Research in Transportation Economics, 39(1), 277-284. 
De Borger, B., \& Proost, S. (2015). The political economy of public transport pricing and supply decisions. Economics of Transportation, 4(1-2), 95-109.

De Borger, B., \& Wouters, S. (1998). Transport externalities and optimal pricing and supply decisions in urban transportation: a simulation analysis for Belgium. Regional Science and Urban Economics, 28(2), 163-197.

De Borger, B., Ochelen, S., Proost, S., \& Swysen, D. (1997). Alternative transport pricing and regulation policies: a welfare analysis for Belgium in 2005. Transportation Research Part D: Transport and Environment, 2(3), 177-198.

Fernandez, E., \& Marcotte, P. (1992). Operators-users equilibrium model in a partially regulated transit system. Transportation Science, 26(2), 93-105.

Ferro, P. S., Behrens, R., \& Wilkinson, P. (2013). Hybrid urban transport systems in developing countries: Portents and prospects. Research in Transportation Economics, 39(1), 121-132.

Glaister, S., \& Lewis, D. (1978). An integrated fares policy for transport in London. Journal of Public Economics, 9(3), 341-355.

Godard, X., \& Ngabmen, H. (2002). Z comme Zemidjan, ou le succès des taxis motos. Les transports et la ville en Afrique au sud du Sahara, Paris, Karthala-Inrets, Coll. Economie et Développement, 397-406.

Gronau, R. (2000). Optimum diversity in the public transport market. Journal of Transport Economics and Policy, 21-41.

Ivaldi, M., \& Vibes, C. (2008). Price competition in the intercity passenger transport market: A simulation model. Journal of Transport Economics and Policy (JTEP), 42(2), 225-254.

Jansson, J.O. (1997) “Theory and practice of transport infrastructure a public transport pricing”, in: G. de Rus and Ch. Nash. Recent Developments in Transport Economics, 74-134.

Jansson, K. (1993). Optimal public transport price and service frequency. Journal of Transport Economics and Policy, 27(1), 33-50.

Kraus, M. (1989). The welfare gains from pricing road congestion using automatic vehicle identification and on-vehicle meters. Journal of Urban Economics, 25(3), 261-281.

Kraus, M. (1991). Discomfort externalities and marginal cost transit fares.Journal of Urban Economics, 29(2), 249-259.

Kristoffersson, I., Börjesson M., \& Valutard, F. (2016). The zero price effect and congestion charging. CTS Working Paper, 17.

Litman, T. (2004). Transit price elasticities and cross-elasticities. Journal of Public Transportation, 7(2), 37-58.

Mirabel, F. (1999). Répartitions modales urbaines, externalités et instauration de péages: Le cas des externalités de congestion et des" externalités modales croisées". Revue économique, 50(5), 10071027.

Mohring, H. (1972). Optimization and scale economies in urban bus transportation. The American Economic Review, 62(4), 591-604.

Parry, I. W., \& Small, K. A. (2009). Should urban transit subsidies be reduced?. American Economic Review, 99(3), 700-724.

Parry, I. W., \& Timilsina, G. R. (2010). How should passenger travel in Mexico City be priced?. Journal of Urban Economics, 68(2), 167-182.

Parry, I., \& Bento, A. (2001). Revenue recycling and the welfare effects of road pricing. Scandinavian Journal of Economics, 103, 645-671.

Pedersen, P. A. (2003). On the optimal fare policies in urban transportation. Transportation Research Part B: Methodological, 37(5), 423-435.

Preston, J. (2008). Public Transport Subsidisation in Ison, S. and Rye, T.(eds) The Implementation and Effectiveness of Transport Demand Management measures: An International Perspective, 10, 189 209. 
Proost, S., \& Van Dender, K. (2008). Optimal urban transport pricing in the presence of congestion, economies of density and costly public funds. Transportation Research Part A: Policy and Practice, 42(9), 1220-1230.

Quinet, E. (2005). Alternative pricing doctrines. Research in Transportation Economics, 14, 19-47.

Small, K. A. (2004). Road pricing and public transport. Research in Transportation Economics, 9(1), 133158.

Small, K. A., Verhoef, E. T., \& Lindsey, R. (2007). The economics of urban transportation. Routledge.

Tirachini, A., \& Hensher, D. A. (2012). Multimodal transport pricing: first best, second best and extensions to non-motorized transport. Transport Reviews, 32(2), 181-202.

Turvey, R., \& Mohring, H. (1975). Optimal bus fares. Journal of Transport Economics and Policy, 266-280.

Verhoef, E. T., Nijkamp, P., \& Rietveld, P. (1997). The social feasibility of road pricing: A case study for the Randstad area. Journal of Transport Economics and Policy, 255-276.

Viton, P. (1983). Pareto-optimal urban transportation equilibria. In T. Keeler (ed.) Research in transportation economics, Greenwich JAI Press, 75-101. 


\section{Appendix}

\section{First conditions for first best:}

$L=B\left(s_{v p}, s_{t p}, s_{t i}\right)-s_{v p} c_{v p}\left(s_{v p}, s_{t p}, s_{t i}, f_{t p}, k_{t p}\right)-s_{t p} c_{t p}\left(s_{v p}, s_{t p}, s_{t i}, f_{t p}, k_{t p}\right)-$ $s_{t i} c_{t i}\left(s_{v p}, s_{t p}, s_{t i}, f_{t p}, k_{t p}\right)+\lambda\left(s_{t p}-f_{t p} k_{t p}\right)$

$\frac{\partial L}{\partial s_{v p}}=\frac{\partial B}{\partial s_{v p}}-c_{v p}-s_{v p} \frac{\partial c_{v p}}{\partial s_{v p}}-s_{t p} \frac{\partial c_{t p}}{\partial s_{v p}}-s_{t i} \frac{\partial c_{t i}}{\partial s_{v p}}=0$

$\frac{\partial L}{\partial s_{t p}}=\frac{\partial B}{\partial s_{t p}}-s_{v p} \frac{\partial c_{v p}}{\partial s_{t p}}-c_{t p}-s_{t p} \frac{\partial c_{t p}}{\partial s_{t p}}-s_{t i} \frac{\partial c_{t i}}{\partial s_{t p}}+\lambda=0$

$\frac{\partial L}{\partial s_{t i}}=\frac{\partial B}{\partial s_{t i}}-s_{v p} \frac{\partial c_{v p}}{\partial s_{t i}}-s_{t p} \frac{\partial c_{t p}}{\partial s_{t i}}-c_{t i}-s_{t i} \frac{\partial c_{t i}}{\partial s_{t i}}=0$

$\frac{\partial L}{\partial f_{t p}}=-s_{v p} \frac{\partial c_{v p}}{\partial f_{t p}}-s_{t p} \frac{\partial c_{t p}}{\partial f_{t p}}-s_{t i} \frac{\partial c_{t i}}{\partial f_{t p}}-\lambda k_{t p}=0$

$\frac{\partial L}{\partial k_{t p}}=-s_{v p} \frac{\partial c_{v p}}{\partial k_{t p}}-s_{t p} \frac{\partial c_{t p}}{\partial k_{t p}}-s_{t i} \frac{\partial c_{t i}}{\partial k_{t p}}-\lambda f_{t p}=0$

$\lambda\left(s_{t p}-f_{t p} k_{t p}\right)=0$

\section{First conditions for second best:}

$$
\begin{aligned}
& L=B\left(s_{v p}, s_{t p}, s_{t i}\right)-s_{v p} c_{v p}\left(s_{v p}, s_{t p}, s_{t i}, f_{t p}, k_{t p}\right)-s_{t p} c_{t p}\left(s_{v p}, s_{t p}, s_{t i}, f_{t p}, k_{t p}\right)- \\
& s_{t i} c_{t i}\left(s_{v p}, s_{t p}, s_{t i}, f_{t p}, k_{t p}\right)+\lambda\left(s_{t p}-f_{t p} k_{t p}\right)+\gamma_{v p}\left(c_{v p}-\frac{\partial B}{\partial s_{v p}}\right)+\gamma_{t p}\left(c_{t p}+\tau_{t p}-\frac{\partial B}{\partial s_{t p}}\right)+ \\
& \gamma_{t i}\left(c_{t i}-\frac{\partial B}{\partial s_{t i}}\right) \\
& \frac{\partial L}{\partial s_{v p}}=\frac{\partial B}{\partial s_{v p}}-c_{v p}-s_{v p} \frac{\partial c_{v p}}{\partial s_{v p}}-s_{t p} \frac{\partial c_{t p}}{\partial s_{v p}}-s_{t i} \frac{\partial c_{t i}}{\partial s_{v p}}+\gamma_{v p}\left(\frac{\partial c_{v p}}{\partial s_{v p}}-\frac{\partial^{2} B}{\partial^{2} s_{v p}}\right)+\gamma_{t p}\left(\frac{\partial c_{t p}}{\partial s_{v p}}-\frac{\partial^{2} B}{\partial s_{v p} \partial s_{t p}}\right)+ \\
& \gamma_{t i}\left(\frac{\partial c_{t i}}{\partial s_{v p}}-\frac{\partial^{2} B}{\partial s_{t i} \partial s_{v p}}\right)=0 \\
& \frac{\partial L}{\partial s_{t p}}=\frac{\partial B}{\partial s_{t p}}-s_{v p} \frac{\partial c_{v p}}{\partial s_{t p}}-c_{t p}-s_{t p} \frac{\partial c_{t p}}{\partial s_{t p}}-s_{t i} \frac{\partial c_{t i}}{\partial s_{t p}}+\gamma_{v p}\left(\frac{\partial c_{v p}}{\partial s_{t p}}-\frac{\partial^{2} B}{\partial s_{t p} \partial s_{v p}}\right)+\gamma_{t p}\left(\frac{\partial c_{t p}}{\partial s_{t p}}-\frac{\partial^{2} B}{\partial^{2} s_{t p}}\right)+ \\
& \gamma_{t i}\left(\frac{\partial c_{t i}}{\partial s_{t p}}-\frac{\partial^{2} B}{\partial s_{t i} \partial s_{t p}}\right)=0 \\
& \frac{\partial L}{\partial s_{t i}}=\frac{\partial B}{\partial s_{t i}}-s_{v p} \frac{\partial c_{v p}}{\partial s_{t i}}-s_{t p} \frac{\partial c_{t p}}{\partial s_{t i}}-c_{t i}-s_{t i} \frac{\partial c_{t i}}{\partial s_{t i}}+\gamma_{v p}\left(\frac{\partial c_{v p}}{\partial s_{t i}}-\frac{\partial^{2} B}{\partial s_{t i} \partial s_{v p}}\right)+\gamma_{t p}\left(\frac{\partial c_{t p}}{\partial s_{t i}}-\frac{\partial^{2} B}{\partial s_{t i} \partial s_{t p}}\right)+ \\
& \gamma_{t i}\left(\frac{\partial c_{t i}}{\partial s_{t i}}-\frac{\partial^{2} B}{\partial^{2} s_{t i}}\right)=0 \\
& \frac{\partial L}{\partial f_{t p}}=-s_{v p} \frac{\partial c_{v p}}{\partial f_{t p}}-s_{t p} \frac{\partial c_{t p}}{\partial f_{t p}}-s_{t i} \frac{\partial c_{t i}}{\partial f_{t p}}-\lambda k_{t p}+\gamma_{v p} \frac{\partial c_{v p}}{\partial f_{t p}}+\gamma_{t p} \frac{\partial c_{t p}}{\partial f_{t p}}+\gamma_{t i} \frac{\partial c_{t i}}{\partial f_{t p}}=0 \\
& \frac{\partial L}{\partial k_{t p}}=-s_{v p} \frac{\partial c_{v p}}{\partial k_{t p}}-s_{t p} \frac{\partial c_{t p}}{\partial k_{t p}}-s_{t i} \frac{\partial c_{t i}}{\partial k_{t p}}-\lambda f_{t p}+\gamma_{v p} \frac{\partial c_{v p}}{\partial k_{t p}}+\gamma_{t p} \frac{\partial c_{t p}}{\partial k_{t p}}+\gamma_{t i} \frac{\partial c_{t i}}{\partial k_{t p}}=0 \\
& \frac{\partial L}{\partial \gamma_{v p}}=-\frac{\partial B}{\partial q_{v p}}+c_{v p}=0 \\
&
\end{aligned}
$$




$$
\begin{aligned}
& \frac{\partial L}{\partial \gamma_{t p}}=-\frac{\partial B}{\partial s_{t p}}+\tau_{t p}+c_{t p}=0 \\
& \frac{\partial L}{\partial \gamma_{t i}}=-\frac{\partial B}{\partial s_{t i}}+c_{t i}=0 \\
& \lambda\left(s_{t p}-f_{t p} k_{t p}\right)=0
\end{aligned}
$$

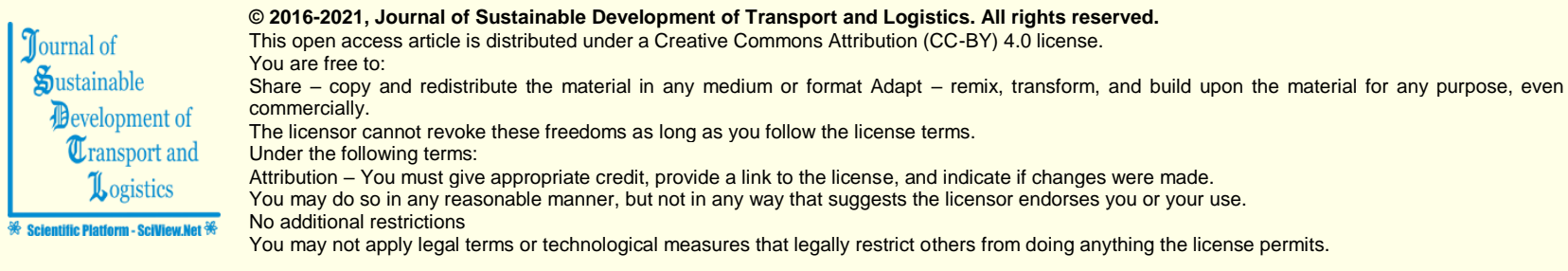

Journal of Sustainable Development of Transport and Logistics (ISSN: 2520-2979) is published by Scientific Publishing House "CSR", Poland, EU and Scientific Publishing House "SciView", Poland, EU

Publishing with JSDTL ensures:

- Immediate, universal access to your article on publication

- High visibility and discoverability via the JSDTL website

- Rapid publication

- Guaranteed legacy preservation of your article

- Discounts and waivers for authors in developing regions

Submit your manuscript to a JSDTL at https://jsdtl.sciview.net/ or submit.jsdt|@sciview.net 